CLINICAL STUDY

\title{
Endogenous subclinical thyroid disorders, physical and cognitive function, depression, and mortality in older individuals
}

\author{
Renate T de Jongh ${ }^{1}$, Paul Lips ${ }^{1}$, Natasja M van Schoor ${ }^{2}$, Kelly J Rijs ${ }^{2}$, Dorly J H Deeg ${ }^{2}$, Hannie C Comijs ${ }^{2,3}$, \\ Mark H H Kramer ${ }^{1}$, Jan P Vandenbroucke ${ }^{4}$ and Olaf M Dekkers ${ }^{4,5}$ \\ ${ }^{1}$ Department of Internal Medicine and Endocrinology, ${ }^{2}$ EMGO Institute for Health and Care Research and ${ }^{3}$ Department of Psychiatry, VU University \\ Medical Center, PO Box 7057, 1007 MB Amsterdam, The Netherlands and Departments of ${ }^{4}$ Clinical Epidemiology, and ${ }^{5}$ Endocrine and Metabolic \\ Diseases, Leiden University Medical Center, Leiden, The Netherlands \\ (Correspondence should be addressed to R T de Jongh; Email: rt.dejongh@vumc.nl)
}

\begin{abstract}
Objective: To what extent endogenous subclinical thyroid disorders contribute to impaired physical and cognitive function, depression, and mortality in older individuals remains a matter of debate.

Design: A population-based, prospective cohort of the Longitudinal Aging Study Amsterdam. Methods: TSH and, if necessary, thyroxine and triiodothyronine levels were measured in individuals aged 65 years or older. Participants were classified according to clinical categories of thyroid function. Participants with overt thyroid disease or use of thyroid medication were excluded, leaving 1219 participants for analyses. Outcome measures were physical and cognitive function, depressive symptoms (cross-sectional), and mortality (longitudinal)

Results: Sixty-four (5.3\%) individuals had subclinical hypothyroidism and 34 (2.8\%) individuals had subclinical hyperthyroidism. Compared with euthyroidism $(n=1121)$, subclinical hypo-, and hyperthyroidism were not significantly associated with impairment of physical or cognitive function, or depression. On the contrary, participants with subclinical hypothyroidism did less often report more than one activity limitation (odds ratio $0.44,95 \%$ confidence interval (CI) $0.22-0.86$ ). After a median follow-up of 10.7 years, 601 participants were deceased. Subclinical hypo- and hyper-thyroidism were not associated with increased overall mortality risk (hazard ratio $0.89,95 \%$ CI $0.59-1.35$ and 0.69 , 95\% CI 0.40-1.20 respectively).

Conclusions: This study does not support disadvantageous effects of subclinical thyroid disorders on physical or cognitive function, depression, or mortality in an older population.
\end{abstract}

European Journal of Endocrinology 165 545-554

\section{Introduction}

Subclinical thyroid disorders are common in older individuals (1). The prevalence of subclinical hyperthyroidism ranges from 1 to $15 \%$ and of subclinical hypothyroidism from 3 to $16 \%$ in individuals aged 60 years and older (1). Although overt thyroid disorders do negatively influence physical and cognitive function (2), associations of subclinical thyroid disorders with these outcome measures are less clear and studies demonstrate contradictory results (3-13). A systematic review of the literature rated the evidence as insufficient to confirm or refute an association of subclinical thyroid disorders with clinical symptoms (2).

Subclinical thyroid disorders are associated with alterations in various cardiovascular risk factors, such as lipid profile, body mass index (BMI), impaired cardiac function, and occurrence of atrial fibrillation $(1,2)$. Nevertheless, meta-analyses including studies in different age categories have shown disagreement on the absence or presence of associations between subclinical thyroid disorders and all-cause mortality (14-18). In individuals aged 60 years and older, endogenous subclinical thyroid disorders have also been reported to have either no significant effect (19-22) or a deleterious effect (23). Remarkably, one study performed in individuals aged 85 years and older, suggested that subclinical hypothyroidism may be related to prolonged survival (12).

To gain more insight into clinical implications of endogenous subclinical thyroid disorders, we aimed to examine cross-sectional associations of thyroid disorders with physical and cognitive function, and depression in a large sample of the older Dutch population. Furthermore, we assessed the relationship between endogenous subclinical thyroid disorders and mortality risk during a follow-up of more than 10 years. 


\section{Subjects and methods}

\section{Participants and mortality}

Data for this analysis was collected within the framework of the Longitudinal Aging Study Amsterdam (LASA), an ongoing cohort study in The Netherlands, which has been described previously (24). Briefly, a random sample of 3107 individuals (aged 55-85 years) participated. At baseline (1992-1993) and every 3 years subsequently a cycle of measurements was carried out. Blood samples for TSH were obtained only in 1995-1996. For financial reasons, TSH was determined in a subset of 1509 participants aged 65 years or older as of January 1, 1996. Older participants were selected because the initial aim was to examine associations of thyroid function with several outcome measures and older individuals demonstrate a higher prevalence of thyroid disorders. Participants without a blood sample or with an insufficient blood sample $(n=239)$ were excluded, leading to 1270 participants with TSH measurements of which over 99\% were Caucasian. The study was approved by the Medical Ethics Committee of the VU University Medical Center, and informed consent was obtained from all participants.

Whether or not death had occurred on June 1, 2007, was determined by collecting data from the registers of the municipalities. The primary causes of death were obtained from the Dutch Central Bureau of Statistics and coded according to the International Classification of Diseases, 10th Revision. Mortality from cardiovascular diseases included deaths due to hypertensive disease (codes I10-I13), ischemic heart disease (codes I20-I25), arrhythmia (codes I44-I49), heart failure (code I50), cerebrovascular disease (codes I60-I69), or atherosclerosis or other diseases of the arteries (codes I70-I78).

\section{Thyroid function}

Morning whole blood samples were collected and centrifuged in 1995-1996. Serum was kept frozen until TSH determination in 2001 in the Endocrinological Laboratory of the VU University Medical Center. Subjects were allowed to eat toast and drink tea but no dairy products. In $\sim 30 \%$ of the study population TSH was also determined immediately to obtain reference values for the local laboratory. These results were communicated to general practitioners and not used in the present analyses. TSH was measured by RIA (Centaur, Bayer Diagnostics) with an interassay co-efficient of variation (CV) of $6 \%$. If TSH was not within the normal range, free thyroxine $\left(\mathrm{T}_{4}\right)$ was measured by a competitive immunoassay (Centaur, Bayer Diagnostics) with an interassay $\mathrm{CV}$ of $7 \%$. If $\mathrm{T}_{4}$ was normal in the presence of an abnormal value of TSH, free triiodothyronine $\left(\mathrm{T}_{3}\right)$ was also measured. Information on the use of levothyroxine $\left(\mathrm{LT}_{4}\right)$ or antithyroid medication was selfreported and accompanied by visual inspection of every container of medication available in the participant's house. This information was obtained at the time of the blood sampling for TSH measurement in 1995-1996 and every 3 years thereafter.

Thyroid function was classified according to the clinical classification (2). Subclinical hypo- and hyperthyroidism were defined as normal $\mathrm{T}_{4}$ and $\mathrm{T}_{3}$ levels (11-22 and 3.5-6.5 pmol/l respectively) together with TSH levels, respectively, above $(>4.5 \mathrm{mU} / \mathrm{l})$ and below $(<0.3 \mathrm{mU} / \mathrm{l})$ normal values. Euthyroidism was defined by normal TSH values ( $\geq 0.3$ and $\leq 4.5 \mathrm{mU} / \mathrm{l})$. In three participants with abnormal TSH values $\mathrm{T}_{4}$ could not be determined and in two participants with abnormal TSH and normal $\mathrm{T}_{4}$ values $\mathrm{T}_{3}$ could not be determined. Thus, 1265 participants could be classified according to clinical categories of thyroid function. We did exclude participants that did not comply with the definition of subclinical thyroid disorders or euthyroidism $(n=22)$ (2), because numbers within other thyroid disorder categories were too small to draw conclusions, resulting in 1243 individuals for analyses.

\section{Physical function}

Physical function was assessed in three ways. i) Total physical performance score, ii) handgrip strength, and iii) self-reported activity limitations.

Total physical performance score was the sum of three different physical performance tests performed in 1995-1996: walking, chair stand, and tandem stand tests. The description and calculation of the scores of these tests is described elsewhere (25). The scores of the three tests were added up to obtain a total score that ranged from 0 (lowest physical performance) to 12 (highest physical performance). Data on total performance score were missing in 66 participants ( $n=37$ abbreviated or preterm terminated interviews; $n=8$ not enough room or refusal, $n=21$ time not measured or test not performed for unknown reasons).

Handgrip strength was assessed using a dynamometer (Takei TKK 5001, Takei Scientific Instruments Co. Ltd, Tokyo, Japan). The maximum strength (kilograms) of two attempts of each hand was averaged. When only one hand could be used, the maximum value of that hand was used $(n=19)$. Handgrip measurements were missing in five participants of which two participants were handicapped at both hands.

Self-reported activity limitations were assessed with a validated questionnaire concerning the degree of difficulty with the following six activities of daily living: climbing stairs, walking 5 min outdoors without resting, getting up and sitting down in a chair, dressing and undressing oneself, using own or public transportation, and cutting one's own toe nails (26). Participants reported a score of zero (not any difficulty) to six (difficulty with all activities). The number was dichotomized to the presence of none or one activity 
limitation or the presence of two or more activity limitations (26). Two or more activity limitations are more likely to be due to an underlying disease than one activity limitation.

\section{Cognitive function and depression}

Cognition was assessed by four tests in 1995-1996: the mini-mental state examination (MMSE), the Raven's colored progressive matrices (RCPM), the coding task (CT), and the auditory verbal learning test (AVLT).

The MMSE is a screening test for global cognitive functioning. The highest score is 30; a score of 23 or less indicates cognitive impairment (27).

The RCPM is used to measure a person's ability for nonverbal and abstract reasoning. In LASA, a short version was used because of time limitations (28). Total scores range from 0 to 24 items, a lower score indicating worse performance.

Information processing speed was measured by an adjusted version of the CT (29). The task consists of three identical trials, in which the respondent has to combine 15 sets of two characters. The total score is defined as the total number of completed characters and ranges from 0 to 45 items.

Memory was measured with an abbreviated version of the AVLT (30). The participant is asked to remember as many words (of 15 nouns) as possible in three trials with an identical word list. The total number remembered is a measure of immediate memory and ranges from 0 to 45 . In addition, the amount remembered after a $20 \mathrm{~min}$ interval is a measure of delayed memory. This is expressed as the percentage of the maximum number remembered during any of the earlier trials and ranges from 0 to more than $100 \%$.

Depression was assessed using the Center for Epidemiologic Studies-Depression Scale (CES-D). Total score ranges from 0 to 60 , a higher score indicating more depressive symptoms. The cut off point for depressive symptoms (CES-D $\geq 16$ ) was pre-established and validated in The Netherlands (31).

Data of the cognitive function tests and depression were missing for several reasons (MMSE, $n=2$; RCPM, $n=58$; CT, $n=58$; AVLT, $n=25$; and CESD, $n=38$ ): an abbreviated interview, preterm termination, too many missing items, physical problems, technical problems, or the cognitive incapability to understand and/or perform the test. In 29 participants at least one of the tests was not performed because of inability to understand and/or perform the given instructions. We performed analyses with the allocation of a score of zero to these missing test results to examine the contribution of this group.

\section{Covariates}

We identified the following potential confounders: alcohol use, smoking status, educational level, number of chronic diseases, BMI, mean arterial pressure (MAP), heart rate, total cholesterol, and physical activity. In addition, BMI is identified as a potential mediator in the relationship between thyroid disorders and physical function. Also, BMI, heart rate, MAP, and total cholesterol are potential mediators in the relationship between thyroid disorders and mortality. The choice of potential confounders and mediators was based on associations with thyroid function and outcome measures, either in our study or in the literature.

Smoking status, alcohol consumption (32), educational level, and the number of chronic diseases (pulmonary disease, cardiac disease, diabetes mellitus, cancer, stroke, arthritis, and peripheral atherosclerosis) was assessed by self-report. Physical activity was assessed with the LASA Physical Activity Questionnaire (LAPAQ) which is described elsewhere (33). Physical activity was not assessed in 37 participants with an abbreviated or preterm terminated interview. Data on educational level, alcohol use, chronic diseases, BMI, MAP, heart rate, and total cholesterol were missing in $2,1,1,22,26,26$, and 31 participants, respectively mostly due to logistic or technical reasons.

\section{Statistical analysis}

Differences in baseline characteristics were tested using one-way ANOVA (normally distributed continuous variables), the Kruskal-Wallis $\mathrm{H}$ test (skewed continuous variables), and the $\chi^{2}$ test (categorical variables).

Logistic and linear regression analyses were used to analyze associations of categories of thyroid function with dichotomous and continuous outcome variables respectively. Cox's proportional hazard model was used to study effects on mortality. The category euthyroidism served as the reference group for all analyses. All analyses were adjusted for age and gender (model 1). In addition, we constructed a model with possible confounders and/or mediators for the separate outcome variables (model 2). In all analyses, the maximum number of complete cases was included.

We chose to present analyses with thyroid function classified in clinical categories and not in percentiles for two reasons. First, this classification is the most appropriate to address the objective of the study, which was to examine associations between subclinical thyroid disorders and outcome measures. Second, the use of percentiles may create TSH categories that are overly broad, which may mask true effects of TSH (34).

\section{Results}

\section{Baseline characteristics and thyroid status}

Participants who used $\mathrm{LT}_{4}$ or antithyroid medication in 1995-1996 were excluded from the cross-sectional analyses $(n=24)$, resulting in 1219 individuals for cross-sectional analyses. Mean age of the participants 
studied for cross-sectional analyses was 75.5 \pm 6.6 years. Gender was almost equally distributed (50.5\% female). The median TSH was $1.5 \mathrm{mU} / \mathrm{l}$ (interquartile range: 1.0-2.3). Thyroid function was normal in 1121 participants (92.0\%). Sixty-four (5.3\%) participants had subclinical hypothyroidism and 34 (2.8\%) participants had subclinical hyperthyroidism. Of the participants with subclinical hypothyroidism 14 (21.9\%) had a TSH above $10.0 \mathrm{mU} / \mathrm{l}$ and of the participants with subclinical hyperthyroidism $13(38.2 \%)$ had a TSH below $0.10 \mathrm{mU} / \mathrm{l}$. Baseline characteristics of the sample studied for cross-sectional analyses stratified by thyroid categories are presented in Table 1.

\section{Physical function}

Table 2 shows results of physical outcome measures according to thyroid categories. Compared with euthyroidism, subclinical hypo- and hyper-thyroidism were not related to differences in total physical performance score. Of the separate physical performance tests, subclinical hyperthyroidism was associated with a higher score on the tandem stand test after correction for potential confounders $(\beta=1.45,95 \%$ confidence interval (CI) $0.08-2.81, P=0.037)$. Results of other physical performance tests did not differ between participants with subclinical thyroid disorders and euthyroidism.

Participants with subclinical hyperthyroidism had lower mean handgrip strength than euthyroid participants, although this difference did not reach statistical significance. Subclinical hypo- and hyper-thyroidism were not associated with a higher amount of selfreported activity limitations. On the contrary, participants with subclinical hypothyroidism did less often report more than one activity limitation. When activity limitations were analyzed as a continuous variable there were no significant differences between the thyroid categories (subclinical hypothyroidism versus euthyroidism, $\beta=-0.05,95 \%$ CI $-0.12-0.02, P=0.19$ and subclinical hyperthyroidism versus euthyroidism, $\beta=-0.31,95 \% \mathrm{CI}-0.81-0.21$, $P=0.24)$.

\section{Cognitive function and depression}

Global cognitive function and depressive symptoms according to thyroid categories are presented in Table 3. Subclinical hypo- and hyper-thyroidism were not related to a higher prevalence of impaired global cognitive function or depression. Similar results were obtained when MMSE and CES-D were analyzed as continuous variables by linear regression analyses (data not shown).

Results for the separate cognitive function tests are shown in Table 4. None of the thyroid categories were associated with limitations in cognitive function tests.

Additional analyses with allocation of a score of zero to participants, who were not able to perform a test because they were not able to understand or perform the instructions, did not materially influence our results.

\section{Mortality}

Participants who started with $\mathrm{LT}_{4}$ or antithyroid medication during follow-up were excluded for the

Table 1 Baseline characteristics of participants studied for cross-sectional analyses stratified by clinical thyroid categories. Data are presented as mean \pm s.D., median (interquartile range) or $n(\%)$ as appropriate.

\begin{tabular}{|c|c|c|c|}
\hline & $\begin{array}{l}\text { Subclinical } \\
\text { hypothyroidism }\end{array}$ & $\begin{array}{l}\text { Subclinical } \\
\text { hyperthyroidism }\end{array}$ & Euthyroidism \\
\hline$n(\%)$ & $64(5.3)$ & $34(2.8)$ & $1121(92.0)$ \\
\hline Female (\%) & $44(68.8)^{\ddagger}$ & $19(55.9)$ & $552(49.2)$ \\
\hline Age (years) & $74.9 \pm 6.8$ & $77.7 \pm 7.0^{*}$ & $75.5 \pm 6.5$ \\
\hline BMI $\left(\mathrm{kg} / \mathrm{m}^{2}\right)$ & $28.1 \pm 4.8(n=63)^{\dagger}$ & $26.6 \pm 4.8(n=33)$ & $26.8 \pm 4.1(n=1112)$ \\
\hline MAP $(\mathrm{mmHg})$ & $109.5 \pm 16.7(n=62)$ & $101.2 \pm 13.8^{*}$ & $106.4 \pm 15.9(n=1107)$ \\
\hline Heart rate (bpm) & $69.7 \pm 11.0(n=62)$ & $71.3 \pm 12.6$ & $68.9 \pm 11.4(n=1107)$ \\
\hline Total cholesterol $(\mathrm{mmol} / \mathrm{l})$ & $6.3 \pm 1.1(n=63)$ & $5.6 \pm 1.1$ & $5.9 \pm 1.5(n=1103)$ \\
\hline TSH (mU/l) & $6.89(5.65-9.59)^{\S}$ & $0.15(0.05-0.24)^{\S}$ & $1.50(1.02-2.11)$ \\
\hline Alcohol consumption & & & $(n=1120)$ \\
\hline Non drinker & $12(35.3)$ & $23(35.9)$ & $255(22.7)$ \\
\hline Light drinker & $14(41.2)$ & $31(48.4)$ & $568(50.7)$ \\
\hline Moderate drinker & $6(17.6)$ & $8(12.5)$ & $224(20.0)$ \\
\hline (Very) excessive drinker & $2(5.9)$ & $2(3.2)$ & $73(6.5)$ \\
\hline \multicolumn{4}{|l|}{ Smoking } \\
\hline Never & $15(44.1)$ & $29(45.3)$ & 385 (34.3) \\
\hline Former & $12(25.3)$ & $27(42.2)$ & $528(47.1)$ \\
\hline Current & $7(20.6)$ & $8(12.5)$ & $208(18.6)$ \\
\hline Education (year) & $8.0 \pm 3.4^{\dagger}$ & $8.9 \pm 3.3$ & $9.0 \pm 3.3(n=1119)$ \\
\hline Physical activity (min/day) & $172.0 \pm 103.2(n=62)^{\dagger}$ & $140.9 \pm 94.7(n=31)$ & $141.7 \pm 97.1(n=1090)$ \\
\hline No. of chronic diseases $(0-7)$ & $1.0(1.0-2.0)$ & $1.0(0-2.0)$ & $1.0(0-2.0 ; n=1120)$ \\
\hline
\end{tabular}

${ }^{*} P=0.06,{ }^{\dagger} P<0.05,{ }^{\ddagger} P<0.01$, and ${ }^{\S} P<0.001$ versus euthyroidism. 
Table 2 Physical performance, handgrip strength, and activity limitations according to different clinical thyroid categories. A higher total physical performance score indicates better physical performance. A higher handgrip strength indicates stronger muscles. A higher score on activity limitations indicates more self-reported activity limitations. Mean \pm s.D. and $n(\%)$ are depicted for the number included in Model 1. Model 1 is adjusted for age and gender. Model 2 is adjusted for age, gender, alcohol use, smoking, number of chronic diseases, physical activity, and body mass index (BMI).

\begin{tabular}{|c|c|c|c|}
\hline & $\begin{array}{l}\text { Subclinical } \\
\text { hypothyroidism }\end{array}$ & $\begin{array}{l}\text { Subclinical } \\
\text { hyperthyroidism }\end{array}$ & Euthyroidism \\
\hline \multicolumn{4}{|c|}{ Total performance score (range 0-12) } \\
\hline Mean \pm S.D. & $7.5 \pm 3.2$ & $7.7 \pm 2.7$ & $7.5 \pm 3.1$ \\
\hline Model $1, \beta(95 \% \mathrm{Cl})$ & $0(-0.1-0.1 ; n=62)$ & $0.6(-0.4-1.6 ; n=28)$ & Reference $(n=1065)$ \\
\hline Model 2, $\beta(95 \% \mathrm{Cl})$ & $0(-0.1-0.2 ; n=62)$ & $0.5(-0.4-1.5 ; n=28)$ & Reference $(n=1056)$ \\
\hline \multicolumn{4}{|c|}{ Handgrip strength (kg; range 0-64) } \\
\hline Mean \pm S.D. & $28.3 \pm 9.2$ & $26.3 \pm 8.7$ & $29.8 \pm 10.2$ \\
\hline Model $1, \beta(95 \% \mathrm{Cl})$ & $0.2(-0.1-0.5 ; n=63)$ & $-1.5(-3.6-0.6 ; n=34)$ & Reference $(n=1119)$ \\
\hline Model 2, $\beta(95 \% \mathrm{Cl})$ & $0.2(-0.1-0.5 ; n=61)$ & $-1.9(-3.9-0.2 ; n=31)^{\dagger}$ & Reference $(n=1081)$ \\
\hline \multicolumn{4}{|c|}{ Activity limitations ( $>1$ vs $\leq 1$ item) } \\
\hline$n(\%)$ & $19(29.7)$ & $9(27.3)$ & $402(36.2)$ \\
\hline Model 1 , OR $(95 \% \mathrm{Cl})$ & $0.63(0.35-1.14 ; n=64)$ & $0.46(0.19-1.12 ; n=33)^{\star}$ & Reference $(n=1104)$ \\
\hline Model 2 , OR $(95 \% \mathrm{Cl})$ & $0.44(0.22-0.86 ; n=62)^{\ddagger}$ & $0.44(0.16-1.22 ; n=30)$ & Reference $(n=1064)$ \\
\hline
\end{tabular}

${ }^{*} P=0.09,{ }^{\dagger} P=0.08$, and ${ }^{\ddagger} P<0.05$ versus euthyroidism.

longitudinal analyses $(n=20$, six in the euthyroid category, 13 in the subclinical hypothyroid category, and one in the subclinical hyperthyroid category). Data whether or not death had occurred from the registers of the municipalities were not available for two euthyroid participants, resulting in 1197 individuals for analysis of mortality. Baseline characteristics did not differ between the sample studied for longitudinal analyses and the sample studied for cross-sectional analyses (data not shown).

During a median 10.7 years of follow-up (interquartile range 5.6-11.2 years), 601 deaths occurred (50.2\%) of which 184 due to cardiovascular causes. Of the 184 deaths to cardiovascular disease, $51(27.7 \%)$ deaths occurred due to ischemic heart disease (one participant with subclinical hypothyroidism and three participants with subclinical hyperthyroidism). Hazard ratio's of all-cause and cardiovascular mortality according to thyroid categories are presented in Table 5 and Kaplan-Meier mortality curves for different thyroid categories are depicted in Fig. 1. The all-cause and cardiovascular mortality risk did not significantly differ between the subclinical thyroid categories and euthyroidism. BMI, cholesterol, heart rate, and MAP were identified as potential mediators of the relationship between subclinical thyroid disease and mortality. Additional analyses demonstrated only minimal changes in hazard ratio $(<10 \%)$ after adjustment for potential mediators separately or combined (data not shown).

Sensitivity analyses were performed after inclusion of participants on thyroid medication at baseline $(n=24)$ and during follow-up $(n=20)$ resulting in analyses of data of 1243 participants for cross-sectional analyses and 1241 participants for longitudinal analyses. This did not materially change the effect estimates (data not shown).

\section{Discussion}

The present findings demonstrated that endogenous subclinical thyroid dysfunction was not associated with impaired physical or cognitive function, or depression

Table 3 Global cognitive function and presence of depressive symptoms according to different clinical thyroid categories. $n(\%)$ is depicted for the number included in Model 1. Model 1 is adjusted for age and gender. Model 2 is adjusted for age, gender, alcohol use, smoking status, educational level, number of chronic diseases, and physical activity.

\begin{tabular}{llll}
\hline & $\begin{array}{l}\text { Subclinical } \\
\text { hypothyroidism }\end{array}$ & $\begin{array}{l}\text { Subclinical } \\
\text { hyperthyroidism }\end{array}$ & Euthyroidism \\
\hline MMSE ( $\leq 23$ vs > 24 points) & & & \\
$n(\%)$ & $7(10.9)$ & $7(20.6)$ & $125(11.2)$ \\
Model 1, OR $(95 \% \mathrm{Cl})$ & $1.01(0.43-2.35 ; n=64)$ & $1.57(0.63-3.92 ; n=34)$ & Reference $(n=1119)$ \\
Model 2, OR (95\% Cl) & $0.81(0.30-2.17 ; n=62)$ & $1.65(0.59-4.63 ; n=31)$ & Reference $(n=1086)$ \\
CES-D (>16 vs $\leq 16$ points) & $11(17.7)$ & $8(25.8)$ & $155(14.2)$ \\
$n(\%)$ & $1.14(0.58-2.27 ; n=62)$ & $1.85(0.79-4.34 ; n=31)$ & Reference $(n=1089)$ \\
Model 1, OR $(95 \% \mathrm{Cl})$ & $1.08(0.53-2.20 ; n=62)$ & $2.12(0.86-5.12 ; n=31)$ & Reference $(n=1087)$ \\
Model 2, OR $(95 \% \mathrm{Cl})$ &
\end{tabular}

MMSE, minimal-mental state examination. A higher score is associated with less global cognitive impairment; CES-D, Center for Epidemiologic Studies-Depression Scale. A higher score indicates more depressive symptoms. 
Table 4 Specific cognitive function tests according to different clinical thyroid categories. Mean \pm s.D. are depicted for the number included in Model 1. Model 1 is adjusted for age and gender. Model 2 is adjusted for age, gender, alcohol use, smoking status, educational level, number of chronic diseases, and physical activity.

\begin{tabular}{|c|c|c|c|}
\hline & $\begin{array}{l}\text { Subclinical } \\
\text { hypothyroidism }\end{array}$ & $\begin{array}{l}\text { Subclinical } \\
\text { hyperthyroidism }\end{array}$ & Euthyroidism \\
\hline \multicolumn{4}{|c|}{ RCPM (number of items; range 1-24) } \\
\hline Mean \pm s.D. & $17.5 \pm 4.0$ & $16.7 \pm 4.7$ & $17.5 \pm 4.0$ \\
\hline Model 1, $\beta(95 \% \mathrm{Cl})$ & $0(-0.2-0.2 ; n=61)$ & $-0.1(-1.5-1.3 ; n=29)$ & Reference $(n=1072)$ \\
\hline Model 2, $\beta(95 \% \mathrm{Cl})$ & $0.1(-0.1-0.3 ; n=61)$ & $-0.3(-1.6-1.0 ; n=29)$ & Reference $(n=1064)$ \\
\hline \multicolumn{4}{|c|}{ CT (number of digits; range 4-45) } \\
\hline Mean \pm S.D. & $24.8 \pm 8.0$ & $23.9 \pm 7.7$ & $25.5 \pm 7.5$ \\
\hline Model $1, \beta(95 \% \mathrm{Cl})$ & $-0 . \overline{1}(-0.4-0.3 ; n=63)$ & $-0 . \overline{3}(-2.7-2.1 ; n=31)$ & Reference $(n=1095)$ \\
\hline Model $2, \beta(95 \% \mathrm{Cl})$ & $0.1(-0.2-0.4 ; n=62)$ & $0.2(-2.0-2.4 ; n=28)$ & Reference $(n=1065)$ \\
\hline \multicolumn{4}{|c|}{$\begin{array}{l}\text { AVLT immediate recall (number of } \\
\text { words; range } 0-42 \text { ) }\end{array}$} \\
\hline Mean \pm s.D. & $18.7 \pm 6.1$ & $18.2 \pm 5.1$ & $19.2 \pm 6.4$ \\
\hline Model 1, $\beta(95 \% \mathrm{Cl})$ & $-0.3(-0.6-0.1 ; n=63)$ & $-0.1(-2.1-1.9 ; n=33)$ & Reference $(n=1104)$ \\
\hline Model 2, $\beta(95 \% \mathrm{Cl})$ & $-0.2(-0.5-0.1 ; n=62)$ & $-0.1(-2.0-1.7 ; n=30)$ & Reference $(n=1073)$ \\
\hline \multicolumn{4}{|c|}{ AVLT delayed recall (\%; range $0-160)$} \\
\hline Mean \pm s.D. & $72 \pm 25$ & $63 \pm 26$ & $67 \pm 26$ \\
\hline Model $1, \beta(95 \% \mathrm{Cl})$ & $0.5(-0.8-1.8 ; n=63)$ & $-1.1(-9.8-7.4 ; n=33)$ & Reference $(n=1097)$ \\
\hline Model 2, $\beta(95 \% \mathrm{Cl})$ & $0.5(-0.7-1.8 ; n=62)$ & $-0.2(-9.0-8.6 ; n=33)$ & Reference $(n=1068)$ \\
\hline
\end{tabular}

RCPM, Raven's colored progressive matrices; CT, coding task; AVLT, auditory verbal learning test.

in a Dutch cohort aged 65 years and older. If anything, the presence of in particular subclinical hypothyroidism might have been related to a slight advantageous effect on self-reported activity limitations. In addition, both subclinical thyroid disorders were not related to an increased risk of mortality during a follow-up of more than 10 years.

\section{Strengths and limitations}

The strengths of this study are the population-based design which enhances generalizability (35). A second strength is the detailed information on physical and cognitive functioning provided by various validated tests. A limitation is that all outcome measures except mortality were analyzed in a cross-sectional way, which cannot exclude cohort effects. In addition, the absence of longitudinal TSH, free $\mathrm{T}_{4}$ and $\mathrm{T}_{3}$ measurements may have contributed to misclassification. However, the physical function tests were performed within a short time interval from TSH measurement. Therefore, it is likely that the measured TSH reflects the thyroid function at time of test performances. However, effects of misclassification and the development of thyroid disorders during follow-up might have affected associations with mortality. In 70\% of the participants TSH was determined only $5-6$ years after blood sampling and for that reason these measurements did not influence the course of the thyroid disorders and treatment decisions of primary care physicians. Regarding the $30 \%$ of the study

Table 5 All-cause and cardiovascular mortality according to different clinical thyroid categories. Model 1 is adjusted for age and gender. Model 2 is adjusted for age, gender, alcohol use, smoking status, physical activity, number of chronic diseases, body mass index, mean arterial pressure, heart rate, and total cholesterol.

\begin{tabular}{llll}
\hline & $\begin{array}{l}\text { Subclinical } \\
\text { hypothyroidism }\end{array}$ & $\begin{array}{l}\text { Subclinical } \\
\text { hyperthyroidism }\end{array}$ & Euthyroidism \\
\hline All-cause mortality & & & \\
At risk $(n)$ & 51 & 33 & 1113 \\
Deceased $(n(\%))$ & $23(45.1)$ & $13(39.4)$ & $565(50.8)$ \\
Model 1, HR $(95 \% \mathrm{Cl})$ & $0.89(0.59-1.35)$ & $0.69(0.40-1.20)$ & Reference \\
At risk $(n)^{\mathrm{a}}$ & 47 & 30 & 1046 \\
Deceased $(n(\%))$ & $29(63.3)$ & $11(36.7)$ & $533(51.0)$ \\
Model 2, HR $(95 \% \mathrm{Cl})$ & $0.91(0.58-1.42)$ & $0.65(0.34-1.19)$ & Reference \\
Cardiovascular mortality & & 33 & 1113 \\
At risk $(n)$ & 51 & $4(12.1)$ & $176(15.8)$ \\
Deceased $(n(\%))$ & $4(7.8)$ & $0.68(0.25-1.83)$ & Reference \\
Model 1, HR $(95 \% \mathrm{Cl})$ & $0.50(0.18-1.34)$ & 30 & 1046 \\
At risk $(n)^{\mathrm{a}}$ & 47 & $4(13.3)$ & Reference \\
Deceased $(n(\%))$ & $4(8.5)$ & $0.71(0.26-1.95)$ & \\
Model 2, HR $(95 \% \mathrm{Cl})$ & $0.55(0.20-1.49)$ & & \\
\hline
\end{tabular}

${ }^{\mathrm{a}}$ Number at risk after exclusion of those cases with missing data on one or more of the potential confounders and/or mediators. 


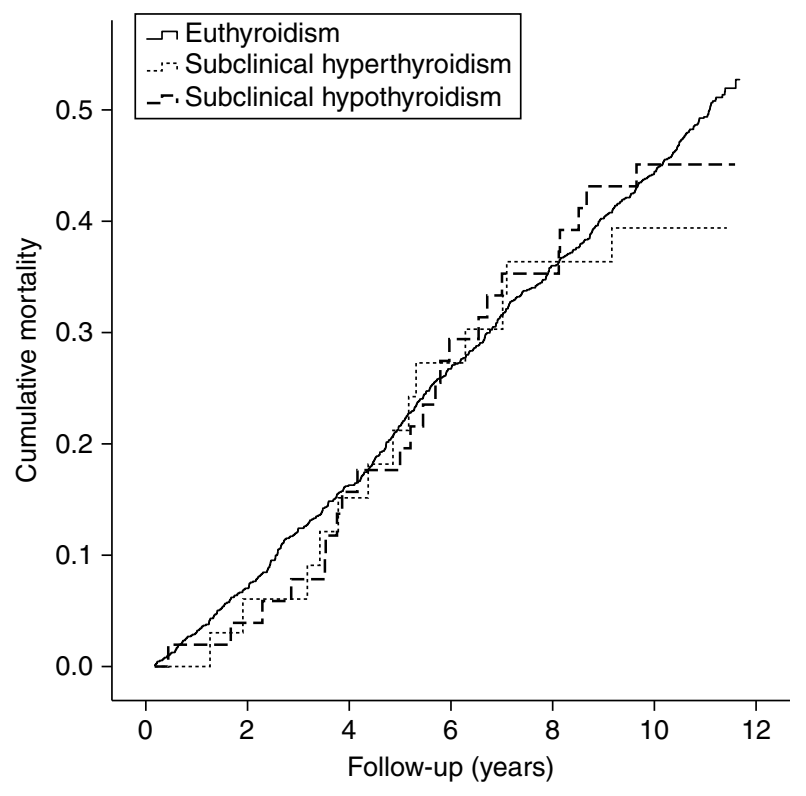

Figure 1 Kaplan-Meier mortality curves according to different thyroid categories.

population in which general practitioners were informed about thyroid function at baseline, we did have data on medication and excluded participants who started thyroid medication during follow-up. However, we lacked information on other treatment modalities such as radioactive iodine or surgery and a direct effect of these treatments on study outcomes and in particular mortality cannot be excluded. In addition, although we adjusted the analysis for a number of comorbidities, residual confounding cannot be ruled out with certainty. Also, our dataset contained a number of missing data and we included only complete cases in the analyses. Part of the data is missing due to technical and logistic reasons and can be assumed to be missing completely at random. However, other data, in particular of physical and cognitive function tests, may be missing not completely at random and thus influence the outcomes. Finally, it should be emphasized that the power of our study to detect small differences in outcomes between subclinical thyroid disorders and euthyroidism was limited. The sample size of this study was in fact predefined, meaning that the data were already available for research purposes as is often the case with observational studies. Since there were 34 patients with subclinical hyperthyroidism and 64 patients with subclinical hypothyroidism, the study was adequately powered to give meaningful estimates for continuous outcomes. As can be seen from Tables 2 and 4, the CI accompanying the calculated effect estimates are rather small, showing that for continuous outcomes our study provides estimates with sufficient precision to be meaningful. However, for binary outcomes, such as mortality, the power will be lower, and negative findings should be interpreted with more caution.

\section{Physical function}

In this study, participants with subclinical thyroid disorders demonstrated similar physical performance as euthyroid participants. Moreover, subclinical thyroid disorders, in particular subclinical hypothyroidism, might even be related to a slight benefit in self-reported activity limitations. This is in agreement with a recent study in a population of similar age, which demonstrated no differences in walking ability between subclinical hypothyroid and euthyroid participants. These data even suggested a slight functional advantage in those with mild TSH elevations (3). In addition, elevated TSH was not associated with impairment of activities of daily living in the Leiden 85-plus study (12). Although impaired muscle strength is a frequent finding in overt hypothyroidism (36), subclinical hypothyroidism is not related to impaired muscle strength in our or other previous studies $(8,37)$. Our results did not exclude a negative effect of subclinical hyperthyroidism on muscle strength. Previously, decreased muscle strength in subclinical hyperthyroidism has been found in proximal muscle groups of the leg (8). In our study, however, the potential impairment of muscle strength in subclinical hyperthyroidism was small and did not coincide with impairments of physical performance or daily functioning. Earlier studies have shown similar exercise performance (7) or arm-hand coordination (4) in individuals with subclinical hyperthyroidism and euthyroidism. Therefore, our findings and earlier studies may suggest that the clinical impact of lower muscle strength in subclinical hyperthyroidism, if present at all, is limited.

\section{Cognitive function and depression}

In our study, subclinical thyroid disorders were not related to impairment in any of the tested domains of cognitive function or to more depressive symptoms. Although cognitive impairment in subclinical hypothyroidism has been shown in studies in populations with a mean age under 65 years $(9,10)$, our results are in line with most $(11,38,39)$ but not all $(40,41)$ studies in populations aged 65 years and older. In addition, studies in younger age groups have shown a clear beneficial effect of $\mathrm{LT}_{4}$ supplementation on cognitive function (10). A recent study in individuals aged 65 years and older, however, did not show such positive effects (13). Studies in older populations examining associations between subclinical hyperthyroidism and cognitive function are scarce. Our results are in line with a large cross-sectional study performed in the UK (38), which also did not demonstrate a relationship, but they contrast with a recent Italian study which showed that subclinical hyperthyroidism was associated with lower MMSE scores (9). This difference may be partly explained by differences in study populations, as the mean MMSE in the latter study was much lower than in 
our study population. Our study also confirms the findings of other studies in which no association was found between subclinical thyroid disorders and depression (42).

\section{Mortality}

Previous meta-analyses show conflicting results on the association of subclinical hyperthyroidism and all-cause mortality $(14,16-18)$. In addition, studies published after these meta-analyses show a similar diversity in results (43-45). This ambiguity in findings may reflect differences in study populations, definitions of subclinical hyperthyroidism, adjustment for potential confounders, duration of follow-up, and presence of comorbidities $(1,45)$. Our population-based cohort study demonstrated that subclinical hyperthyroidism, in contrast to overt thyroid disorders, was not related to increased all-cause mortality risk. This is in line with three other population-based studies in a similar age group $(19,21,22)$. In contrast, a TSH $<0.5 \mathrm{mU} / \mathrm{l}$ compared with TSH $\geq 0.5 \mathrm{mU} / \mathrm{l}$ was associated with increased all-cause mortality in a population of 60 years and older (23). However, in that study, participants with an elevated TSH were included in the reference category. An additional analysis of our data using a similar reference category (TSH $\geq 0.5 \mathrm{mU} / \mathrm{l}$ ) resulted in a hazard ratio for all-cause mortality of $1.17(95 \%$ CI 0.81-1.71). Further, the relationship was found for a follow-up time of 2-5 years, but not for the total followup time of 10 years, which the authors explained by the high amount of deceased participants at the end of the study. The Kaplan-Meier mortality curves of our data demonstrate that even in a shorter follow-up time subclinical hyperthyroidism is not likely to be associated with increased all-cause mortality risk.

Although meta-analyses examining the relationship between subclinical hypothyroidism and all-cause mortality also show disagreement on the presence or absence of a relationship (14-18), all studies in populations aged over 60 years (19-23) are in agreement with our study and demonstrate the absence of significant relationships between subclinical hypothyroidism and all-cause mortality. In addition, a recent meta-analysis based on individual data analyses demonstrated a small but not significant increased risk of all-cause mortality in individuals aged 65-79 years and no increased risk in individuals aged 80 years and above (15). Results from the Leiden 85-plus study suggested that in a very old population an elevation of TSH may even result in an increased life span (12). This difference illustrates that effects of subclinical thyroid disorders cannot be extrapolated over different age groups. In addition, meta-analyses suggest a possible relationship of subclinical hypothyroidism with cardiovascular morbidity and mortality in particular in younger populations and in the presence of TSH concentrations of $7 \mathrm{mU} / \mathrm{ml}$ or above $(14,15)$. Although our data does not suggest a relationship between subclinical thyroid disorders and increased cardiovascular mortality, the number of deaths due to cardiovascular disease and in particular coronary heart disease was too small to draw definite conclusions.

\section{Clinical implications}

Our data demonstrates the absence of relationships between subclinical thyroid disorders, on the one hand, and disadvantageous effects on physical and cognitive function, depression, or mortality, on the other hand. In older populations screening for thyroid disorders is often performed by primary care physicians, internists and geriatricians in the presence of physical or cognitive impairments, or depressive symptoms. Findings of thyroid function tests in the subclinical range may not automatically imply an explanation for the complaints and subsequent initiation of treatment. Indeed, the presence of symptoms specific for thyroid dysfunction, such as palpitations or weight loss, necessitate thyroid function testing, and may warrant treatment for subclinical thyroid disorders. However, only randomized controlled trials in large cohorts can definitely answer the question whether treatment of subclinical thyroid dysfunction will affect morbidity and mortality in older individuals.

\section{Declaration of interest}

The authors declare that there is no conflict of interest that could be perceived as prejudicing the impartiality of the research reported.

\section{Funding}

This work is based on data from the Longitudinal Aging Study Amsterdam (LASA), which is financially supported by the Dutch Ministry of Public Health, Welfare, and Sports.

\section{Acknowledgements}

The authors thank Jan Poppelaars for processing and distributing the data.

\section{References}

1 Biondi B \& Cooper DS. The clinical significance of subclinical thyroid dysfunction. Endocrine Reviews 200829 76-131. (doi:10. 1210/er.2006-0043)

2 Surks MI, Ortiz E, Daniels GH, Sawin CT, Col NF, Cobin RH, Franklyn JA, Hershman JM, Burman KD, Denke MA, Gorman C, Cooper RS \& Weissman NJ. Subclinical thyroid disease: scientific review and guidelines for diagnosis and management. Journal of the American Medical Association 2004291 228-238. (doi:10. 1001/jama.291.2.228)

3 Simonsick EM, Newman AB, Ferrucci L, Satterfield S, Harris TB, Rodondi N \& Bauer DC. Subclinical hypothyroidism and functional mobility in older adults. Archives of Internal Medicine 2009169 2011-2017. (doi:10.1001/archinternmed.2009.392)

4 Schlote B, Nowotny B, Schaaf L, Kleinbohl D, Schmidt R, Teuber J, Paschke R, Vardarli I, Kaumeier S \& Usadel KH. Subclinical 
hyperthyroidism: physical and mental state of patients. European Archives of Psychiatry and Clinical Neuroscience 1992241 357-364. (doi:10.1007/BF02191961)

5 Razvi S, Weaver JU, Vanderpump MP \& Pearce SH. The incidence of ischemic heart disease and mortality in people with subclinical hypothyroidism: reanalysis of the Whickham Survey cohort. Journal of Clinical Endocrinology and Metabolism 201095 1734-1740. (doi:10.1210/jc.2009-1749)

6 Reuters VS, Teixeira PF, Vigario PS, Almeida CP, Buescu A, Ferreira MM, de Castro CL, Gold J \& Vaisman M. Functional capacity and muscular abnormalities in subclinical hypothyroidism. American Journal of the Medical Sciences 2009338 259-263. (doi:10.1097/MAJ.0b013e3181af7c7c)

7 Portella RB, Silva JL, Wagman MB, de Oliveira FP, Buescu A \& Vaisman M. Exercise performance in young and middle-aged female patients with subclinical hyperthyroidism. Thyroid 2006 16 731-735. (doi:10.1089/thy.2006.16.731)

8 Brennan MD, Powell C, Kaufman KR, Sun PC, Bahn RS \& Nair KS. The impact of overt and subclinical hyperthyroidism on skeletal muscle. Thyroid 200616 375-380. (doi:10.1089/thy. 2006.16.375)

9 Ceresini G, Lauretani F, Maggio M, Ceda GP, Morganti S, Usberti E, Chezzi C, Valcavi R, Bandinelli S, Guralnik JM, Cappola AR, Valenti G \& Ferrucci L. Thyroid function abnormalities and cognitive impairment in elderly people: results of the Invecchiare in Chianti study. Journal of the American Geriatrics Society 200957 89-93. (doi:10.1111/j.1532-5415.2008.02080.x)

10 Begin ME, Langlois MF, Lorrain D \& Cunnane SC. Thyroid function and cognition during aging. Current Gerontology and Geriatrics Research 200847 4868. (doi:10.1155/2008/474868)

11 Park YJ, Lee EJ, Lee YJ, Choi SH, Park JH, Lee SB, Lim S, Lee WW, Jang HC, Cho BY, Woo JI \& Kim KW. Subclinical hypothyroidism (SCH) is not associated with metabolic derangement, cognitive impairment, depression or poor quality of life $(\mathrm{QoL})$ in elderly subjects. Archives of Gerontology and Geriatrics 201050 e68-e73. (doi:10.1016/j.archger.2009.05.015)

12 Gussekloo J, van Exel E, de Craen AJ, Meinders AE, Frolich M \& Westendorp RG. Thyroid status, disability and cognitive function, and survival in old age. Journal of the American Medical Association 2004292 2591-2599. (doi:10.1001/jama.292.21.2591)

13 Parle J, Roberts L, Wilson S, Pattison H, Roalfe A, Haque MS, Heath C, Sheppard M, Franklyn J \& Hobbs FD. A randomized controlled trial of the effect of thyroxine replacement on cognitive function in community-living elderly subjects with subclinical hypothyroidism: the Birmingham Elderly Thyroid study. Journal of Clinical Endocrinology and Metabolism 201095 3623-3632. (doi:10.1210/jc.2009-2571)

14 Ochs N, Auer R, Bauer DC, Nanchen D, Gussekloo J, Cornuz J \& Rodondi N. Meta-analysis: subclinical thyroid dysfunction and the risk for coronary heart disease and mortality. Annals of Internal Medicine 2008148 832-845.

15 Rodondi N, den Elzen WP, Bauer DC, Cappola AR, Razvi S, Walsh JP, Asvold BO, Iervasi G, Imaizumi M, Collet TH, Bremner A, Maisonneuve P, Sgarbi JA, Khaw KT, Vanderpump MP, Newman AB, Cornuz J, Franklyn JA, Westendorp RG, Vittinghoff E \& Gussekloo J. Subclinical hypothyroidism and the risk of coronary heart disease and mortality. Journal of the American Medical Association 2010304 1365-1374. (doi:10.1001/jama. 2010.1361)

16 Haentjens P, Van Meerhaeghe A, Poppe K \& Velkeniers B. Subclinical thyroid dysfunction and mortality: an estimate of relative and absolute excess all-cause mortality based on timeto-event data from cohort studies. European Journal of Endocrinology 2008159 329-341. (doi:10.1530/EJE-08-0110)

17 Volzke H, Schwahn C, Wallaschofski H \& Dorr M. Review: the association of thyroid dysfunction with all-cause and circulatory mortality: is there a causal relationship? Journal of Clinical Endocrinology and Metabolism 200792 2421-2429. (doi:10. $1210 / \mathrm{jc} .2007-0179$ )

18 Singh S, Duggal J, Molnar J, Maldonado F, Barsano CP \& Arora R. Impact of subclinical thyroid disorders on coronary heart disease, cardiovascular and all-cause mortality: a meta-analysis. International Journal of Cardiology $2008 \mathbf{1 2 5}$ 41-48. (doi:10.1016/ j.ijcard.2007.02.027)

19 Cappola AR, Fried LP, Arnold AM, Danese MD, Kuller LH, Burke GL, Tracy RP \& Ladenson PW. Thyroid status, cardiovascular risk, and mortality in older adults. Journal of the American Medical Association 2006295 1033-1041. (doi:10.1001/jama. 295.9.1033)

20 Rodondi N, Newman AB, Vittinghoff E, de Rekeneire N, Satterfield S, Harris TB \& Bauer DC. Subclinical hypothyroidism and the risk of heart failure, other cardiovascular events, and death. Archives of Internal Medicine 2005165 2460-2466. (doi:10.1001/archinte.165.21.2460)

21 van den Beld AW, Visser TJ, Feelders RA, Grobbee DE \& Lamberts SW. Thyroid hormone concentrations, disease, physical function, and mortality in elderly men. Journal of Clinical Endocrinology and Metabolism 200590 6403-6409. (doi:10. 1210/jc.2005-0872)

22 Bauer DC, Rodondi N, Stone KL \& Hillier TA. Thyroid hormone use, hyperthyroidism and mortality in older women. American Journal of Medicine 2007120 343-349. (doi:10.1016/j.amjmed. 2006.04.034)

23 Parle JV, Maisonneuve P, Sheppard MC, Boyle P \& Franklyn JA. Prediction of all-cause and cardiovascular mortality in elderly people from one low serum thyrotropin result: a 10-year cohort study. Lancet 2001358 861-865. (doi:10.1016/S0140-6736 (01)06067-6)

24 Deeg DJ, van Tilburg T, Smit JH \& de Leeuw ED. Attrition in the Longitudinal Aging Study Amsterdam. The effect of differential inclusion in side studies. Journal of Clinical Epidemiology 200255 319-328. (doi:10.1016/S0895-4356(01)00475-9)

25 Wicherts IS, van Schoor NM, Boeke AJ, Visser M, Deeg DJ, Smit J, Knol DL \& Lips P. Vitamin D status predicts physical performance and its decline in older persons. Journal of Clinical Endocrinology and Metabolism 200792 2058-2065. (doi:10.1210/jc.2006-1525)

26 Stel VS, Pluijm SM, Deeg DJ, Smit JH, Bouter LM \& Lips P. Functional limitations and poor physical performance as independent risk factors for self-reported fractures in older persons. Osteoporosis International 200415 742-750. (doi:10.1007/ s00198-004-1604-7)

27 Tombaugh TN \& McIntyre NJ. The mini-mental state examination: a comprehensive review. Journal of the American Geriatrics Society $199240922-935$.

28 Smits CH, Smit JH, van den Heuvel N \& Jonker C. Norms for an abbreviated Raven's coloured progressive matrices in an older sample. Journal of Clinical Psychology 199753 687-697. (doi:10.1002/(SICI)1097-4679(199711)53:7 < 687::AID-JCLP6 > 3.0.CO;2-F)

29 van den Heuvel N. Information processing speed: coding task. In Autonomy and well-being in the aging population I: report from the Longitudinal Aging Study Amsterdam 1992-1993. Edn 1, pp 59-64. Eds DJ Deeg \& M Westendorp-de-Seriere. Amsterdam: VU University Press, 2009.

30 Dik MG, Jonker C, Bouter LM, Geerlings MI, van Kamp GJ \& Deeg DJ. APOE-epsilon 4 is associated with memory decline in cognitively impaired elderly. Neurology 200054 1492-1497.

31 Beekman AT, Deeg DJ, Van Limbeek J, Braam AW, De Vries MZ \& Van Tilburg W. Criterion validity of the Center for Epidemiologic Studies Depression scale (CES-D): results from a community-based sample of older subjects in The Netherlands. Psychological Medicine 199727 231-235. (doi:10.1017/S003 3291796003510)

32 Garretsen HFL Probleemdrinken, prevalentiebepaling, beinvloedende factoren en preventiemogelijkheden: theoretische overwegingen overwegingen en onderzoek in Rotterdam (dissertation in Dutch). Lisse, The Netherlands: Swets and Zeitlinger BV, 1983.

33 Stel VS, Smit JH, Pluijm SM, Visser M, Deeg DJ \& Lips P. Comparison of the LASA physical activity questionnaire with a 7-day diary and pedometer. Journal of Clinical Epidemiology 2004 57 252-258. (doi:10.1016/j.jclinepi.2003.07.008) 
34 Greenland S \& Rothman KJ. Fundamentals of epidemiologic data analysis. In Modern Epidemiology, edn 3, ch. 13, pp 213-237, Eds KJ Rothman, S Greenland \& TL Lash. Philadelphia: Lippincott, Williams \& Wilkins 2008.

35 Dekkers OM, von Elm E, Algra A, Romijn JA \& Vandenbroucke JP. How to assess the external validity of therapeutic trials: a conceptual approach. International Journal of Epidemiology 2010 39 89-94. (doi:10.1093/ije/dyp174)

36 Cakir M, Samanci N, Balci N \& Balci MK. Musculoskeletal manifestations in patients with thyroid disease. Clinical Endocrinology 200359 162-167. (doi:10.1046/j.1365-2265.2003.01786.x)

37 Moon MK, Lee YJ, Choi SH, Lim S, Yang EJ, Lim JY, Paik NJ, Kim KW, Park KS, Jang HC, Cho BY \& Park YJ. Subclinical hypothyroidism has little influences on muscle mass or strength in elderly people. Journal of Korean Medical Science 201025 1176-1181. (doi:10.3346/jkms.2010.25.8.1176)

38 Roberts LM, Pattison H, Roalfe A, Franklyn J, Wilson S, Hobbs FD \& Parle JV. Is subclinical thyroid dysfunction in the elderly associated with depression or cognitive dysfunction? Annals of Internal Medicine 2006145 573-581.

39 Luboshitzky R, Oberman AS, Kaufman N, Reichman N \& Flatau E. Prevalence of cognitive dysfunction and hypothyroidism in an elderly community population. Israel Journal of Medical Sciences 199632 60-65.

40 Cook SE, Nebes RD \& Halligan EM. Memory impairment in elderly individuals with a mildly elevated TSH: the role of processing resources, depression and cerebrovascular disease. Aging, Neuropsychology, and Cognition 20029 175-184. (doi:10.1076/anec.9. 3.175.9610)
41 Manciet G, Dartigues JF, Decamps A, Barberger-Gateau P, Letenneur L, Latapie MJ \& Latapie JL. The PAQUID survey and correlates of subclinical hypothyroidism in elderly community residents in the southwest of France. Age and Ageing 199524 235-241. (doi:10.1093/ageing/24.3.235)

42 Engum A, Bjoro T, Mykletun A \& Dahl AA. An association between depression, anxiety and thyroid function-a clinical fact or an artefact? Acta Psychiatrica Scandinavica 2002106 27-34. (doi:10.1034/j.1600-0447.2002.01250.x)

43 Sgarbi JA, Matsumura LK, Kasamatsu TS, Ferreira SR \& Maciel RM. Subclinical thyroid dysfunctions are independent risk factors for mortality in a 7.5-year follow-up: the JapaneseBrazilian thyroid study. European Journal of Endocrinology 2010 162 569-577. (doi:10.1530/EJE-09-0845)

44 Ittermann T, Haring R, Sauer S, Wallaschofski H, Dorr M, Nauck M \& Volzke H. Decreased serum TSH levels are not associated with mortality in the adult northeast German population. European Journal of Endocrinology $2010 \mathbf{1 6 2}$ 579-585. (doi:10.1530/EJE-09-0566)

45 Biondi B. Invited commentary: cardiovascular mortality in subclinical hyperthyroidism: an ongoing dilemma. European Journal of Endocrinology 2010162 587-589. (doi:10.1530/EJE09-1095)

Received 12 May 2011

Revised version received 30 June 2011

Accepted 18 July 2011 